\title{
MOVEMENT PARASITE: Parking Management through Legislation and Objects
}

\author{
MASHA HUPALO \\ Aarhus School of Architecture
}

The current paper articulates a relational logic of parking spaces and its strategic employment. According to Michel Serres, the parasite "is, first of all, the elementary relation" that constructs the subject. Seen in this way parking is the parasite that marks a beginning and an end of every trip. These nodes of stillness can influence movement and with it an urban fabric in which this stillness resides. Two different urban fabrics and approaches are explored in case studies: an array of surface parking lots in Downton Los Angeles and a monumental parking garage of the Mountain Dwelling in Copenhagen. What this analysis brings forward is the potency of an architectural object to enhance the effect of the spatial software of planning legislation. There is no opposition between thinking of the city in terms of flows and arranging spatial compositions of buildings. Instead, the movement parasites of parking can be deployed as strategic catalysts in a broad regulatory field.

\section{INTRODUCTION}

The current paper explores a phenomenon of parking as a rare intersection of infrastructure networks, land use in metropolitan regions and technological mobilities. It is an embodiment of dependencies between these elements. Taken from this broad field, the paper addresses two questions. First, it sets out to illuminate the potential of repetitive parking spaces to create a favourable context for the later development of the territories they serve. In doing so, this inquiry addresses two case studies: an array of surface parking lots in Downton Los Angeles and a monumental parking garage of the Mountain Dwelling in Copenhagen. The second question addresses two approaches to transforming urban fabric through parking manipulating legislative software and installing exceptional objects - and how they can be seen in relation to each other.

One might ask why parking? What is so exceptional about it? Nothing, and this mundane existence that it leads in urban, suburban, exurban and all other territories occupied by humans is what makes it worthy of the further inspection. Parking spaces are nodes of stillness in mobility networks that are meant to house an automobile - a symbol of freedom, movement, technological progress, and independence - that remains parked on average for 95 per cent of the time. The absurdity of this arrangement is self-evident but in it also lies its strength. With all its tensions and confrontations, the management of stillness - what parking essentially is - can influence movement and with it an urban fabric in which this stillness resides.

\section{PARKING AND DESTINATION: THE EMERGENCE OF MINIMUM REQUIREMENTS}

When outlining the primary logic of parking, it becomes obvious that it is not an option but a vital necessity to have a place to stop, and - until we have reached a much-promised urbanity serviced by shared self-driving fleets of cars - to stand. The availability of this space allows journeys to happen altogether. The parking space marks a beginning and an end of every trip. Seen in this light every parking space, every spot for car storage is an extension of the road, and at the very same time, it is a part of the built city fabric. But no matter how decisive it is in providing mobility potentials, when taken out of its infrastructural context, trimmed out of the network, it loses its meaning and with it vital importance.

In other words, parking needs an environment to operate. Just like any other parasite creature. At the highest level of generality, a parasite exists only in relation. Without engaging at a typological analysis at this point, we can highlight that one of the most important attributes of a parasite is the specificity of the conditions which it finds suitable for entering and settling. In other words, it needs an environment, a milieu that acts as a generous and accommodating host for developing a relationship. Michel Serres underscores that the parasite "is, first of all, the elementary relation." ${ }^{1}$ A parasite for him is a quasi-object, like a ball or a ferret, that makes up the collective when being passed around, and constructs an individual or a subject once it stops. A ball becomes an object only when the subject holds it, and the surrounding of this subject turns into a witness. It becomes a game of getting defined: "This quasi-object is not an object, but it is one nevertheless, since it is not a subject, since it is in the world; it is also a quasi-subject since it marks or designates a subject who, without it, would not be a subject."2

With this in mind, when we return to the issue of parking and destination, it becomes evident that unless the parasitic quasiobject of parking marks the shop, restaurant, museum, or concert hall, the destination runs a risk of not even being one. It is not recognised to be of any interest or importance. While remaining an event of merely local importance parking as a movement parasite when introduced or removed from the city organism can cause growth and decline, concentration and decentralisation. But it was not always a quasi-object. An introduction of consolidated parking was a planners' solution in the first half of the twentieth century to the problem of the street congestion in major American cities. This congestion 


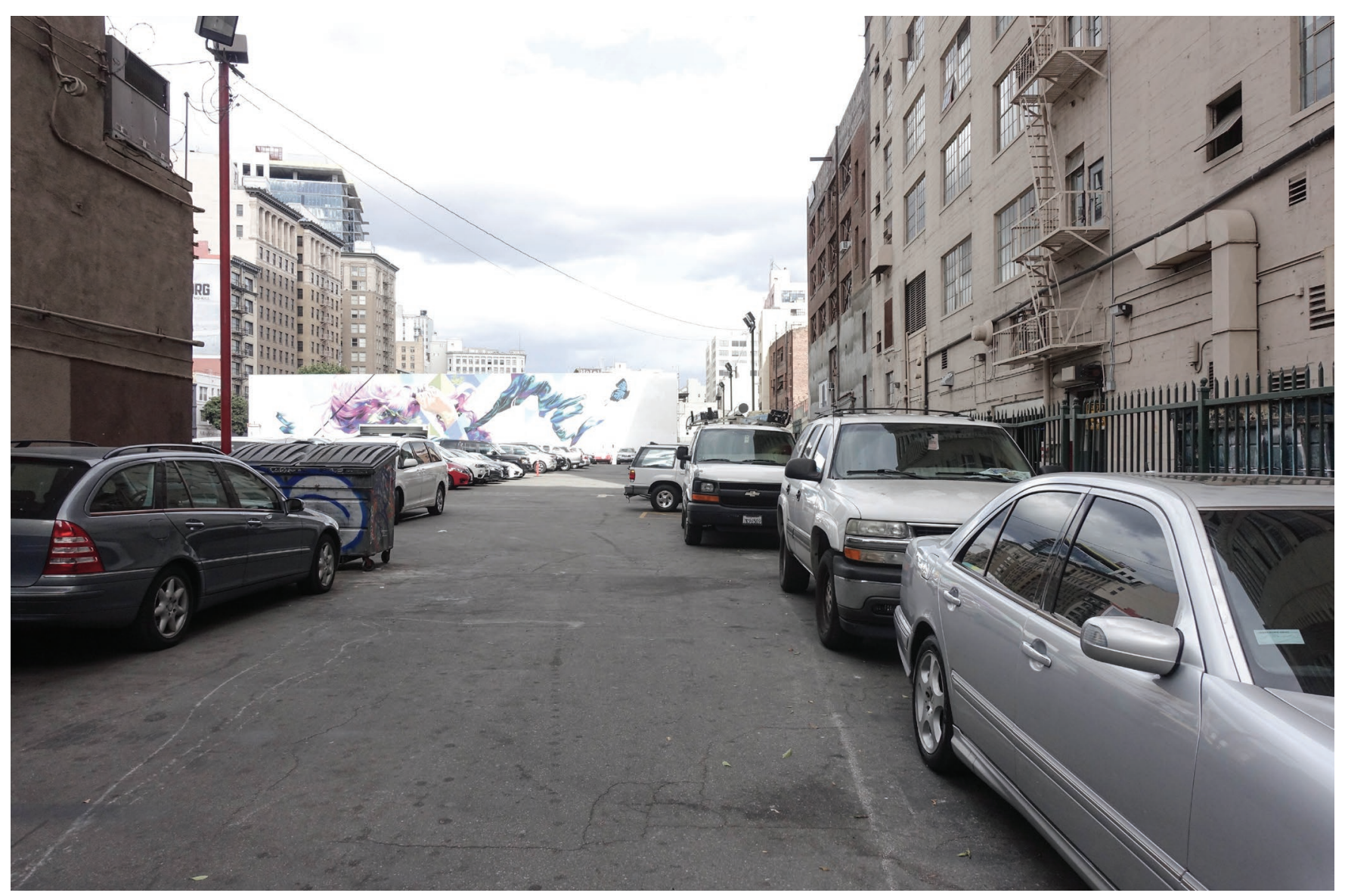

Figure 1: 710 South Spring Street, Downtown Los Angeles.

was primarily caused by curb-parked automobiles and automobiles cruising around the blocks in search of parking. The best response seemed to be an introduction of minimum parking requirements for every building that despite its best intentions did more harm than good over the last half a century. ${ }^{3}$ Donald Shoup thoroughly explained and criticised the practice of saturating the city with free parking facilities in his 750-page book The High Cost of Free Parking. It was originally published in 2005 by the American Planning Association and due to the success of its comprehensive analysis was revised and released in 2011. In this study, Shoup not only explains the problem of ample free parking but also identifies decisive reforms to improve an urban environment. His first policy proposal is to remove off-street parking requirements and allow developers to determine it themselves. At the same time, on-street parking has to be priced in a way to balance supply and demand. Finally, the parking revenue generated from on-street parking should be used for improving public services on the metered areas. ${ }^{4}$

Since whole new rationality can be imposed on the city only through managing these parasites, we have to acknowledge that they are a great instrument not only for creating pleasurable pedestrian areas but also for generating and maintaining social separations, segmenting or splintering territories.
They are always a part of the larger infrastructural network with embedded spatial politics. This critical line of thinking about cities in terms of flows, socio-technical processes and integrated networks has been developed in the last two decades but mainly is preoccupied with such elements as tolled private highways, malls, skywalk systems and broadband communications: "Together, these linked complexes of networks and spaces provide recessionary "network spaces" for elites and upper-income groups in the contemporary metropolis - shopping malls, entertainment and leisure developments, gated communities, "smart" homes and the like." 5 A similar agency can be assigned to parking as terminals of automobile networks. Dynamic pricing of parking, municipal park-and-ride facilities, in lieu fees paid by employers to discourage driving, and residential parking permits among many other strategies have a potential to create "secessionary enclaves" 6 as well as fragmented and privatised streets. It is highly important to keep in mind the whole range of outcomes that can be achieved by managing parking: change the land use and demographics, give space to additional housing, or allow to preserve historical developments. The current paper introduces two case studies which aim at improving an urban fabric but inevitably produce trade-offs. Both of them describe a mechanism of transforming the city fabric by their strategic placement or removal. Even though they are located 


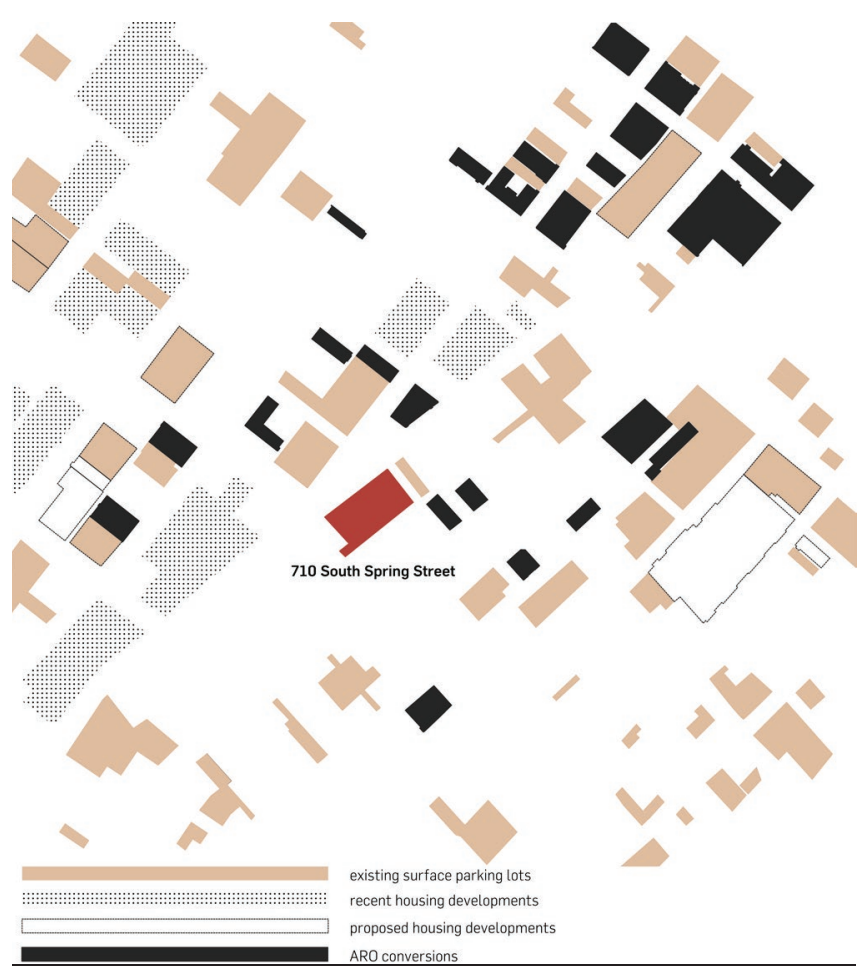

Figure 2. Observing the unfolding changes in the inspected area of Downtown Los Angeles leads to a speculative conclusion that a discussed parking lot might be the next property to attract real estate developers.

in cities that belong to different generations of motorization which implies different housing typologies, patterns of density, car ownership numbers and public transit choices two cases can be viewed as a theoretical replication of tackling spatial and non-spatial problems of a traditional city through mundane infrastructural spaces.

\section{SURFACE PARKING LOT: SUBTRACTION AND REUSE}

With this in mind, we can take a look at the first case of the public parking lot at the 710 South Spring Street (figure 1). Five dollars per every fifteen minutes, ten dollars after four o'clock, maximum twenty dollars and ten dollars' flat rate on Saturday and Sunday. Located in between Fashion District, Historical District and South Park, it is one of the largest parking lots in Downtown Los Angeles. A morphologically modest asphalt surface consists of five land parcels, all of them zoned for Light Manufacturing (C5 zone) in General Plan Land Use, with a total assessed land value of $\$ 7,539,659 .^{7}$

Two entrances - one from South Spring Street and one from 9th Street - maximise the convenience for parkers of adjacent land uses. New Mart Building full of fashion showrooms, a number of bars and restaurants, refurbished offices and newly converted apartments make up a mixture of potential users. It is safe to say that parking lots like this one predominantly serve their immediate surroundings. Visually the area is saturated with gaps in between turn-of-the-century office buildings. There are four other public parking lots in a five-hundred-meter radius, excluding underground garages for apartment buildings and assigned customer parking facilities. Taken collectively, a system of more than one hundred asphalt surfaces, equipped only with ATMs and valets, managed by several companies like Joe's Auto Parks, Athena Parking and Paragon Parking is a visible outcome of Downtown's competition with commercial centres of highincome residential communities.

After World War 2 declining business activity in Downtown caused a simultaneous decline of property values. One of the main reasons that made office and service providers leave the city centre was an automobile traffic and parking congestion. In addition to this high tax assessment on land in downtown encouraged the tearing down of unprofitable buildings and turning the land into parking. The reduction of property value and tax revenues made it impossible for the majority of American cities to maintain streets and mass transit in downtowns. As for the property owners, they saw the usage of cleared land for parking as a temporary measure in anticipation of future redevelopment. With very little thought given to the appearance of the urban fabric, demolition was fragmenting downtowns in a random fashion. ${ }^{8}$ The office building volumes became victims of a rapidly growing car ownership: "A building envelope is closely tied to economic and logistic formulas for optimising the consumption of goods and entertainment and may be as volatile as the market."9

In an attempt to stop the deterioration of cultural heritage city planners and preservationists mobilised their forces and generated the first version of the Adaptive Reuse Ordinance in 1990. This policy concerned downtown buildings in a commercial or R-5 (high density) residential zone constructed before July 1, 1974, and extended possibilities of their conversion. Most importantly it relaxed the parking requirements for an eligible building if it were converted to dwelling units, joint living and working quarters, guest rooms in hotels or a combination of them. No new parking spaces were required with existing ones had been reserved for residential tenants or turned public. ${ }^{10}$ The intent was to create a dense "24-hour city" with mixed commercial and residential uses, improve air quality and reduce vehicle trips. A few decades later a strikingly successful result is hard not to acknowledge, but it came with a price - a rise in land prices by as much as $400 \%$ since the early 2000 s. $^{11}$

Additionally, most of the suitable buildings have been already reconfigured, and highly skilled contractors are required for this kind of transformations. In this climate, ground-up developments on the former surface parking lots greatly outnumber conversions. These lots in proximity to jobs and services are "endangered species" that disappear to give way to new condominium towers that come equipped with parking and more residents. With $\$ 28,5$ billion investment in Downtown Los Angeles starting from 1999, it is easy to see 


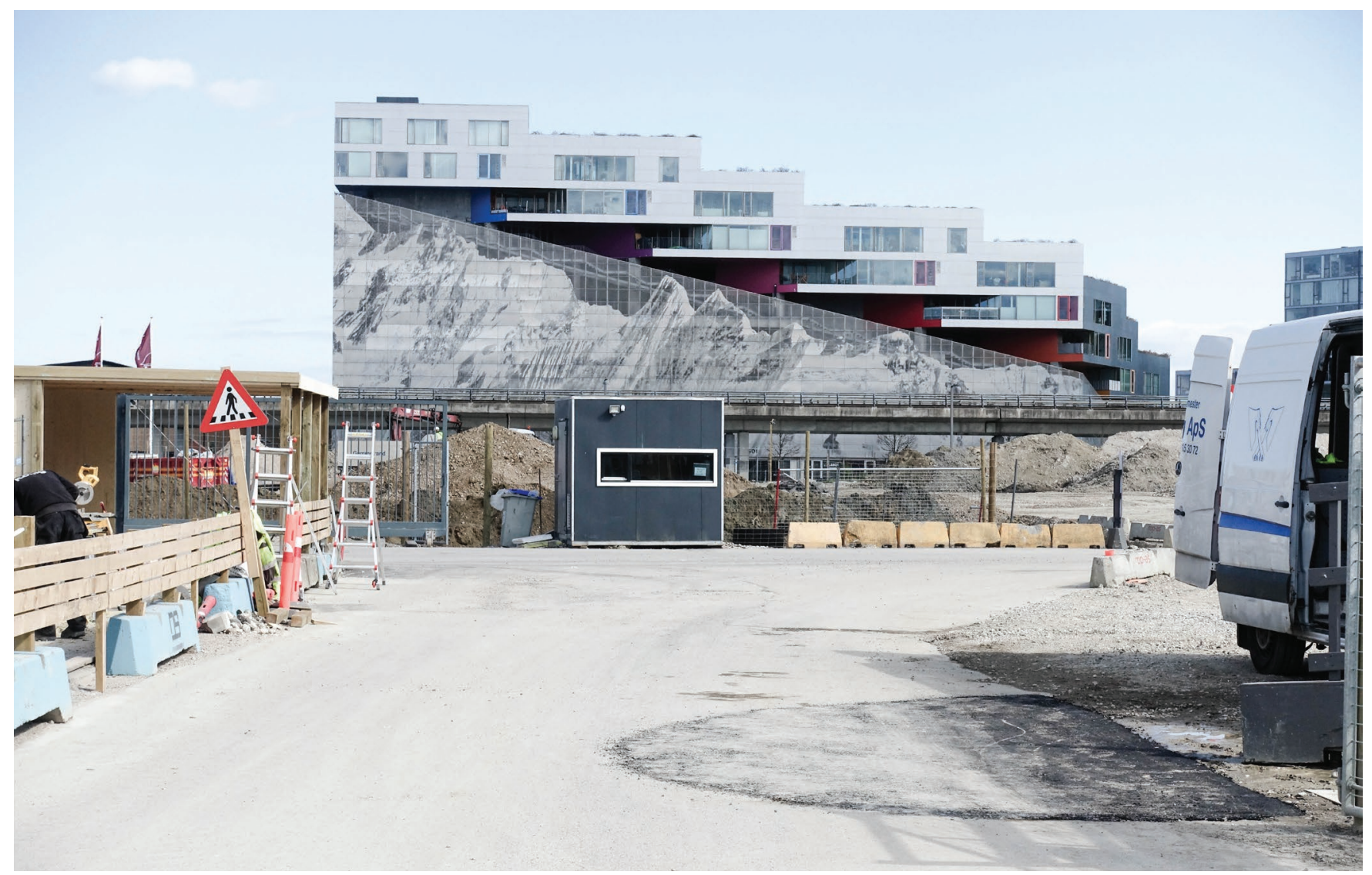

Figure 3. Mountain Dwelling, Ørestad, Copenhagen, west façade.

how it runs the risk to turn into another location of storing global capital in the form of unoccupied apartments. The near future will show whether Downtown will become the victim of its success. In the meantime, a look at the pattern of the recent housing developments, conversions of former commercial buildings and proposed condominium towers makes evident that a discussed parking lot is very likely to give place to a new apartment building (figure 2).

\section{THE SITE AND ITS RIPPLE EFFECT}

The main distinction between an above-described case study and the following one is the choice of engagement with parking regulation tools. Adaptive Reuse Ordinance is an operating system hidden in plain sight that determines the relationships between the components. Keller Easterling describes such phenomena as active forms: "Active forms are markers of disposition, and disposition is the character of an organisation that results from the circulation of these active forms within it. Since these forms are always changing, as in the complex of disposition, they cannot be catalogued as elemental building blocks or terms in a glossary." ${ }^{12}$ Not in an attempt to contradict this way of organising urban activities but rather to enhance the second case study is centered around a building - Mountain Dwelling in Copenhagen. It is a part of a larger plan of managing parking facilities in $\varnothing$ restad area and simultaneously an exceptional architectural object that has an additional power of encouraging certain activities. Like the first case Mountain Dwelling it is a part of contextual set of relationships but serves as a reminder of disciplinary powers of architecture. It is site specific and this might be the source of its power to attract tourists, convince residents and employees, or function as a viewing platform of place for daily exercising. ${ }^{13}$

But what is the site of the movement parasite? The multiplicity of understandings in different disciplines that take part in the design of the physical environment increases confusion and complicates collaboration. It is a significant obstacle that reveals embedded conflicts and contradictions in fields of architecture, urban design, urban planning, and landscape architecture. First and foremost the site is a "relational construct": "Each built project creates new forces within its own area and also modifies and influences systems that both reach beyond the site and operate within it." ${ }^{14}$ The site can act as a dynamic composition of three areas. The first is the area of control that is a close relative of the building site with strictly delineated limits. The second one - the area of influence reflects a cumulative interplay among public policy decisions, shifting market conditions, and technological innovations among many other forces that influence the plot. And lastly, 


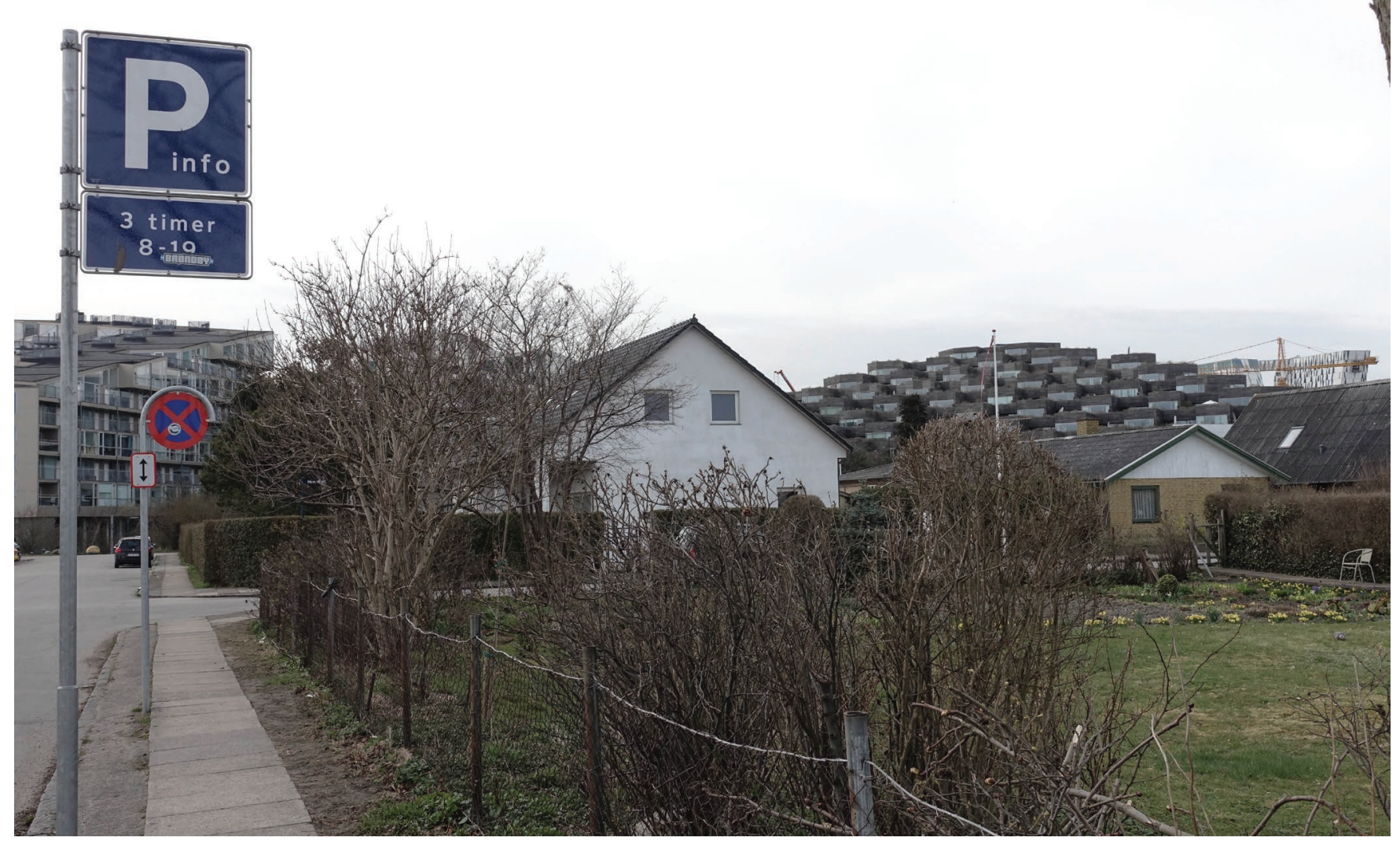

Figure 4. Mountain Dwelling, Ørestad, Copenhagen, east façade.

the area of effect corresponds to noteworthy alterations of the surrounding territories. ${ }^{15}$ These three areas connect quantifiable aspects of human experience, form-finding gestures and intangible practices. All of this is to say that the site is a complex construct, and despite its veneer of stability and permanence invites a negotiation of diverse interests.

What are the implications of this definition of the site for our issue at hand? It is a place of countless decisions of very different sorts that introduces an incremental change. It can be read as a trace of processes, an information system of potentials and relationships. Put more bluntly; it is a site of negotiation, a site for architects, urban planners, traffic engineers, investors, business owners, developers, drivers and pedestrians to debate their interests. Mostly in a mute mode. Through the cascade of documents, they reach agreements, establish a hierarchy, and develop a physical presence of the negotiation process.

\section{MONOLITH PARKING GARAGE: CONSOLIDATION AND TRANSITION}

Seen in this way, as a result of negotiations between different actors who plan, develop, manage, inhabit, govern, profit and occupy the territory served by a parking garage, Mountian Dwelling in Ørestad district in Copenhagen is a captivating case study of a subtle agreement. This multi-level parking garage designed by world-renown architecture practice BIG has 480 parking spots covered by a layer of 80 apartments with spacious terraces and views over $\emptyset$ restad (figure 3 ). The ratio of parking to housing signifies the intention of this facility to consolidate the storage of vehicles and serve both residents and employees of the area. It is one of the six free-standing garages that are cheaper to build, easier to reuse and encourage pedestrian activity. The last notion is interesting in light of the criticism of the last ten years: $\emptyset$ restad has been continuously called dull, monotonous and homogenous. In the eyes of architecture critics, it failed to provide an urban vitality that was expected from it. ${ }^{16}$ This unusually dense development for Copenhagen is essentially a sixth "finger" that has been added to a regional plan of infrastructural corridors, a continuation of an outstanding Transit Oriented Development. In 1947 the "Finger Plan" was a solution to housing a growing urban population along rail lines while keeping territories in between them intact. Fifty years later Copenhagen was facing a challenge of rethinking its spatial policies due to the mass movement of wealthier families to suburbs beyond the city boundary. Megaproject of the $\varnothing$ restad New Town was a project of a public state and city-owned $\varnothing$ restad Development Corporation with cheap government-backed loans. ${ }^{17}$ The top-down planned 
modernist linear city of $\varnothing$ restad is designed to be highly accessible by public transport and bicycles. Car parking is restricted for both residents and visitors with an intent to decrease car ownership and commuting. Then why are we still talking about a garage next to the mass transit in probably the most bike-friendly city in the world?

First, even if the residents prefer to bike to their destinations, on the weekends the majority of families would make a trip to the coast, to the summerhouse or to one of the numerous museums that are usually located outside of the metropoli$\tan$ area. The second reason is slightly more speculative. To begin with, to the east of the Mountain Dwelling there is a single-family housing area Elmegarden with one-storey high buildings (figure 4). These were summer-only residencies that have been zoned as permanent only in 2005. ${ }^{18}$ Divided only by a narrow footpath and a canal this is an unexpected neighbour of the garage. This spatial arrangement can be explained by the Mountain Dwelling being a translator between single-family suburban sites and a dense environment of transit-oriented development of $\varnothing$ restad. It manages to merge two identities: on the one hand, it is a shared, consolidated and mixed-use development in proximity of the Metro stop; and on the other, it is a penthouse apartment building with individual gardens and no possible views of neighbours. In other words, as part of the wider planning framework it complies with the narrative of urban density and progressive mobility strategies, while, as a piece with a distinctive spatial character it embodies a more intricate idenntity of the site.

\section{ENHANCING THE SPATIAL SOFTWARE}

An above described perception of free standing parking structures that are at the same time a part of the mobility hierarchy can be traced back to some of the first attempts of architects to regulate traffic through introduction of objects. Louis I. Kahn in 1952 traffic studies for Philadelphia identified that "a key architectural element in his proposal was the strategic positioning of parking structures to encourage the use of private transportation to reach the city center, thereby conceptualizing the city as the orchestration of vehicular movement through the organization of expressways as "rivers" and parking structures as "harbors." ${ }^{19}$ Continuing this line of thought this article argues that parking regulation - be it legislative, economical or architectural - is a means to engage with the urban fabric in a productive way. However, the article by no means suggests that parking management can be seen as an independent regulator of density, land use, building envelopes or any other measurement of the city. What this analysis brings forward is the potency of an architectural object to enhance the effect of the spatial software of urban planning legislation. There is no opposition between thinking of the city in terms of flows and arranging spatial compositions of buildings. Instead, the movement parasites of parking can be deployed as strategic catalysts in a broad regulatory field.

\section{ENDNOTES}

1 Michel Serres, The Parasite (Minneapolis: University of Minnesota Press, 2007), 224.

2 Serres, 225.

3 Minimum parking requirements are laws that require new buildings to provide parking spaces based on square footage or other parameters like the number of seats, number of bowling alleys, number of beds and many others.

4 Donald Shoup, Parking and the City (New York: Routledge, 2018), 3.

5 Steve Graham and Marvin Shane, Splintering Urbanism: Networked Infrastructures, Technological Mobilities and the Urban Condition (London; New York: Routledge, 2001), 220.

6 Graham and Shane, 228.

7 Calculations based on Zone Information and Map Access System of Los Angeles: http://zimas.lacity.org

8 John A. Jakle and Keith A. Sculle, Lots of Parking: Land Use in a Car Culture (Charlottesville: University of Virginia Press, 2005), 62.

9 Keller Easterling, Critical Spatial Practice 4-Subtraction (Berlin: Sternberg Press, 2014), 13.

10 Subdivision 26 of Los Angeles Planning and Zoning Code, 2001.

11 Ryan Vaillancourt, "With Adaptive Reuse Options Limited, Developers Adapt," Los Angeles Downtown News, January 28, 2013. http://www.ladowntownnews.com/news/with-adaptive-reuse-options-limited-developers-adapt/ article_268d0cca-6748-11e2-a8b4-001a4bcf887a.html.

12 Keller Easterling, Extrastatecraft: The Power of Infrastructure Space (London; New York: Verso, 2014), 73.

13 For a wide variety of imaginative parking structures see: Simon Henley, The Architecture of Parking (London: Thames \& Hudson, 2009).

14 Carol J. Burns and Andrea Kahn, Site Matters: Design Concepts, Histories, and Strategies (New York: Routledge, 2004), xii.

15 Burns and Kahn, xii.

16 Lea Olsson and Jan Loerakker, "The Story Behind Failure: Copenhagen's Business District Ørestad," Failed Architecture, September 12, 2013. https://failedarchitecture.com/ the-story-behind-the-failure-copenhagens-business-district-orestad/.

17 Richard Knowles, "Transit Oriented Development in Copenhagen, Denmark: From the Finger Plan to Ørestad," World Transit Research, January 1, 2012: 254

18 Lokalplan \#393 “Elmegården,” 2005, 3.

19 Pier Vittorio Aureli, “Appropriation, Subdivision, Abstraction: A Political History of the Urban Grid," Log 44 (Fall 2018): 163. 